\title{
CONTRIBUIÇÃO AOS ESTUDOS PARA SELEÇÃO DE ÁREAS PARA CONSTRUÇÃO DE ATERROS SANITÁRIOS
}

\section{Diana da Cruz Fagundes Bueno'}

RESUMO: Destinar os resíduos sólidos urbanos e dispor os rejeitos adequadamente tem sido um dos principais desafios enfrentados pelas administrações públicas municipais. De acordo com a Lei oㅜ 12.305/2010 que institui a Política Nacional de Resíduos Sólidos (PNRS), na elaboração dos Planos Municipais de Gestão Integrada dos Resíduos Sólidos (PMGIRS), entre seus conteúdos mínimos está a necessidade de identificação de áreas favoráveis à disposição final ambientalmente adequada de rejeitos. No entanto, há falta de conhecimento dos gestores públicos e equipes de apoio quanto aos estudos que devem ser realizados para a identificação dessas áreas favoráveis. Neste contexto, apresentamos algumas contribuições teóricas, com base em levantamento bibliográfico, para a seleção de áreas adequadas à construção de aterros sanitários. Falamos também da importância da análise de viabilidade técnica e econômica de instalação de aterros sanitários intermunicipais consorciados, visto que, após o advento da Lei dos Consórcios (Lei no 11.107/2005), no momento de acessar as fontes de recursos financeiros do governo federal, as iniciativas consorciadas são privilegiadas em detrimento das demandas isoladas, e que a Lei ㄲo 12.305/2010, em seu art. 18, $\S^{10}$ tem como um dos objetivos, priorizar os municípios que optarem por soluções consorciadas intermunicipais para a gestão dos resíduos sólidos.

1 Bacharel e Mestre em Geografia. Doutoranda do Programa de Pós-graduação em Geografia da Universidade Estadual Paulista - UNESP, Faculdade de Ciências e Tecnologia, Rua Roberto Simonsen, 305, Presidente Prudente, São Paulo, Brasil. Fone: (12) 3207-9201. dianafag@yahoo.com.br 
Palavras-chave: Meio Ambiente. Resíduos Sólidos. Aterro Sanitário.

\section{INTRODUÇÃO}

Os problemas ambientais relativos aos resíduos sólidos urbanos vem se agravando cada vez mais com o aumento do consumo de produtos e mercadorias.

O caráter consumista da sociedade moderna atrelado à utilização de produtos descartáveis tem permitido uma grande produção de resíduos. Esses resíduos, muitas vezes descartados de forma inadequada, tem agravado os problemas de poluição do ar, do solo e da água. (BROLLO, 2001).

Um aspecto importante sobre esta questão é o tipo de resíduo que tem sido gerado nas cidades, pois suas características também tem se modificado nas últimas décadas pelo acesso, cada vez maior, da população ao consumo de bens industrializados. O uso, por exemplo, de materiais plásticos e vidros, que apresentam uma degradação lenta, é um fator de extrema importância a ser avaliado, quando o assunto é sua destinação.

Segundo Hendges (2011), o Ministério do Meio Ambiente elaborou uma versão preliminar do Plano Nacional de Resíduos Sólidos com o apoio do Instituto de Pesquisa Econômica Aplicada (IPEA), em que fez um diagnóstico da situação dos resíduos sólidos, tendo 2008 como ano de referência. Tal produto utilizou informações da Pesquisa Nacional de Saneamento Básico (PNSB), do Sistema Nacional de Informação em Saneamento (SNIS), da Associação Brasileira de Empresas de Limpeza Pública e Resíduos Especiais (ABRELPE), da Associação Brasileira da Indústria Química, da Associação Brasileira do Alumínio e do Ministério das Minas e Energia.

Os dados apresentados nesses documentos apontam para um aumento na quantidade de resíduos sólidos coletados em todo o país, mas também da produção total e individual produzida. O que mostra que técnicas como a compostagem, a coleta seletiva e reciclagem, tem sido cada vez mais adotadas em nosso país. No entanto, conforme Caseiro e Quitho (2004), esses mecanismos ainda são insuficientes para atender à demanda de resíduos sólidos gerados nos centros urbanos, tornando necessária a utiliza- 
ção de aterros como forma de destinação do material descartado não passível de reaproveitamento.

O levantamento realizado pelo Ministério das Cidades também traz a informação de que no Brasil, somente $29 \%$ dos municípios utilizam aterros sanitários, e $71 \%$ ainda utilizam aterros em vala e lixões. E que, dos 2.906 lixões distribuídos em 2.810 municípios, 98\% estão localizados em municípios de pequeno e médio porte.

A forma mais adequada de dispor os resíduos sólidos urbanos é em aterro sanitário. No aterro sanitário a disposição dos resíduos visa proteger o meio ambiente e saúde pública e favorecer a segurança e o bem estar da população. Para tanto, são aplicadas técnicas de engenharia e normas operacionais específicas para confinar os resíduos na menor área possível e reduzir ao mínimo o seu volume, cobrindo-os com uma camada de terra ou material inerte, quantas vezes forem necessárias. Os aterros sanitários contem ainda, sistemas de impermeabilização da base e laterais, sistemas de drenagem do chorume, tratamento, remoção segura e queima dos gases produzidos (FEAM, 2002).

No entanto, como vimos acima, muitos municípios, principalmente os de pequeno porte $^{2}$, ainda utilizam o aterro em vala para a disposição dos resíduos. Conforme Nascimento (2001) apud Brollo (2004) os aterros em vala, também denominados aterros controlados não passam de "lixões maquiados", pois apresentam praticamente os mesmos problemas dos lixões, como a poluição das águas superficiais e subterrâneas, do solo e do ar.

Essa forma de disposição constitui alternativa aceitável pelos órgãos ambientais para municípios com menos de 25 mil habitantes e geração de lixo inferior a 10 toneladas/dia (SMA, s.d.), por se tratar de local onde os resíduos devem ser depositados, compactados e recobertos diariamente por uma camada de material inerte ${ }^{3}$.

Mas, não podemos compreender a adoção de tal medida como solução para o problema da disposição dos resíduos, pois quando o aterro controlado é utilizado, muitos

\footnotetext{
${ }^{2}$ Neste texto considera-se como município de pequeno porte aquele que atende às seguintes condições: I população de até trinta mil habitantes, senso do IBGE (2000); e II - geração diária de resíduos sólidos

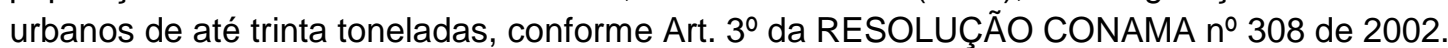

${ }^{3}$ Secretaria Estadual do Meio Ambiente. Site: http://www.ambiente.sp.gov.br. Acesso em: 05_10_10.
} 
problemas ambientais relativos à poluição dos solos, da água e do ar continuam existindo. O que nos permite compreender que ainda há uma demanda muito grande por estudos e ações voltadas à adequada disposição dos resíduos sólidos urbanos em aterros sanitários.

Possíveis ações político-administrativas para solucionar problemas referentes à definição do local e do modelo de disposição dos resíduos sólidos urbanos só podem se consolidar através do correto embasamento técnico e científico. Assim, questionamentos sobre o local onde os resíduos sólidos urbanos estão sendo depositados, os critérios que tem sido utilizados para a seleção dessas áreas e o modelo mais adequado para a disposição final dos resíduos evidenciam a necessidade de estudos criteriosos relacionados aos Planos Municipais de Gerenciamento Integrado dos Resíduos Sólidos Urbanos para a seleção desses locais.

Compreendendo que a disposição dos resíduos sólidos é apenas uma parte do ciclo, cujo gerenciamento adequado deve contemplar ações que visem à redução, à reutilização e à reciclagem dos resíduos gerados, neste texto discutiremos alguns procedimentos a serem utilizados nos estudos para seleção de áreas adequadas à instalação de aterros sanitários.

\section{CRITÉrios PARA SELEÇÃo de Áreas PARA INSTALAÇÃo de ATERROS SANITÁRIOS}

Executar um projeto de aterro sanitário significa realizar previamente uma série de estudos que vão desde a realização de vários levantamentos quanto à viabilidade técnica e econômica, até a elaboração do projeto. (LIMA, 2002).

No processo histórico de escolha de áreas para instalação de aterros, o que se pode identificar é que as áreas eram selecionadas muito mais com base na proximidade da área produtora dos resíduos e na disponibilidade de grandes cavas (de mineração), do que em quaisquer outros critérios. (HAMER, 2003 apud LINO, 2007).

De acordo com Brollo (2004) a prática de disposição inadequada dos resíduos é herdada de um passado sem planejamento ambiental, responsável por muitas áreas 
degradadas. Essa prática pode ser atribuída tanto ao desconhecimento dos efeitos nocivos das substâncias químicas no ambiente e na saúde como também à negligência humana que permitiu o abandono de áreas degradadas que acabaram se tornando passivos ambientais para as gerações presentes e futuras.

A Lei 12.305 de 02 de agosto de 2010 institui a Política Nacional de Resíduos Sólidos. Esta lei, regulamentada pelo decreto 7.404 de 23 de dezembro de 2010, em seu capítulo 2, Art. $3^{\circ}$, item VIII, pressupõe a "distribuição ordenada dos rejeitos em aterros, observando normas operacionais específicas de modo a evitar danos ou riscos à saúde pública e à segurança e a minimizar os impactos ambientais adversos". Sendo ainda, proibido o lançamento de resíduos sólidos in natura a céu aberto, conforme cap. 6, art. 47, item II da referida lei. (DIÁRIO OFICIAL DA UNIÃO, 2010).

Para o cumprimento desta lei, os municípios brasileiros tiveram prazo encerrado em 02 de agosto de 2012 para apresentar seus Planos de Gestão Integrada de Resíduos Sólidos, estando os municípios descumpridores deste prazo, impedidos de receber repasses de recursos estaduais e federais para o setor de resíduos sólidos.

Além do prazo para os municípios elaborarem os planos de gestão integrada de resíduos sólidos, a Lei no 12.305/2010 também define o prazo até 02/08/2014 para disposição final ambientalmente adequada dos resíduos sólidos.

No entanto, de acordo com Associação Brasileira de Agências de Regulação (ABAR), em novembro de 2013 apenas 30\% dos 5.570 municípios brasileiros estavam concluindo seu Plano Nacional de Saneamento Básico, previsto pela lei 11.445/2007. (ABAR, 2013).

Em 2011, em pesquisa de informações básicas municipais realizadas pelo Instituto Brasileiro de Geografia e Estatística (IBGE), apenas 609 municípios informaram que haviam concluído a elaboração dos planos de saneamento.

De acordo com o Ministério das Cidades e Abar (2013), a partir desta lei tornou-se obrigatória a elaboração dos planos. E os municípios que ainda não cumpriram com sua elaboração ficam impossibilitados de receber recursos da união para aplicar no setor de saneamento devido ao fato do Decreto 7.217/2010 ter determinado que, a partir de janeiro de 2014, o acesso a verbas federais está condicionado à existência do plano. 
A própria Agência Brasil (2013) realizou uma pesquisa intitulada Regulação 2013 abrangendo 2.716 municípios que possuem agências reguladoras no setor de saneamento básico. Os resultados da pesquisa demonstraram que apenas $34 \%$ dos municípios concluíram o plano em 2012.

Dentre os principais problemas apontados na pesquisa para a não elaboração desses planos estão: a falta de recursos municipais e o fato de as prefeituras contarem com equipe de apoio pouco qualificada, tanto para elaborar quanto para implementar o plano.

O artigo 19, item II, da Lei no 12.305/2010 diz que na elaboração dos Planos Municipais de Gestão Integrada dos Resíduos Sólidos, entre seus conteúdos mínimos está a necessidade de "identificação de áreas favoráveis para disposição final ambientalmente adequada de rejeitos, observando o plano diretor de que trata o $\S 1^{\circ}$ do artigo. 182 da Constituição Federal e o Zoneamento Ambiental, se houver". (DIÁRIO OFICIAL DA UNIÃO, 2010).

No entanto, há falta de conhecimento e muitas dúvidas dos gestores e equipe quanto aos estudos que devem ser realizados para a identificação de áreas favoráveis à disposição final dos rejeitos, de modo a garantir condições ambientalmente seguras.

Nesse contexto, apresentamos algumas contribuições teóricas, com base em levantamento bibliográfico, quanto à seleção de áreas para a implantação de aterros sanitários.

Primeiramente, é importante esclarecer que a Lei ํㅡ 12.305/2010 diferencia os conceitos de destinação e disposição final ambientalmente adequada de resíduos sólidos.

Conforme capítulo II, art. 3ํㅡ, item VII da lei, a destinação final ambientalmente adequada dos resíduos

[...] inclui a reutilização, a reciclagem, a compostagem, a recuperação e o aproveitamento energético dos resíduos ou outras destinações admitidas pelos órgãos competentes [...], de modo a evitar danos ou riscos à saúde pública e à segurança e a minimizar os impactos ambientais adversos. (DIÁRIO OFICIAL DA UNIÃO, 2010). 
Já a disposição final ambientalmente adequada dos resíduos, apresentada no capítulo II, art. $3^{\circ}$, item VIII, refere-se à

"[...] distribuição ordenada de rejeitos em aterros, observando normas operacionais específicas de modo a evitar danos ou riscos à saúde pública e à segurança e a minimizar os impactos ambientais adversos. (DIÁRIO OFICIAL DA UNIÃO, 2010).

Tais conceitos nos auxiliam na compreensão de que a disposição em aterro sanitário deve ser realizada somente quando já foram esgotadas todas as possibilidades de reutilização, reciclagem ou tratamento do resíduo, que na ocasião, torna-se rejeito.

Mas, antes da disposição dos resíduos é preciso definir qual área apresenta melhores condições do ponto de vista técnico, ambiental, social para receber um aterro sanitário. Para que a escolha do local seja aprovada é preciso obedecer a uma série de critérios.

LINO (2007) destaca que o pesquisador Rohde, em 1989, foi um dos primeiros a propor um método que permite uma visão geral da área de estudo, bem como suas possibilidades e restrições. Assim, para Rohde (1989), apud Lino (2007), constituem etapas para seleção de áreas para implantação de aterros sanitários:

- Levantamento de dados gerais e estudos em aerofotos: início da análise ambiental e espacial do problema (levantamento de dados geológico-pedológicos e geotécnicos, hidrológicos, de infra-estrutura e compatibilidade);

- Integração com o sistema de transporte: preocupação com as distâncias. Por exemplo, distâncias superiores a $20 \mathrm{~km}$ entre o último ponto de coleta e o aterro são consideradas inviáveis do ponto de vista econômico;

- Estudos topográficos: topografia regional: permite avaliar aos aspectos hidrológicos, de drenagens, possíveis contaminações. Levantamento topográfico planialtimétrico detalhado: mostra aclives e declives em curvas de nível e perfis, cobrindo a bacia contribuinte, vias de acesso e pontos de referência;

- Estudos geológico-geotécnicos: para indicação da constituição do solo, a permeabilidade, a capacidade de carga, a profundidade do lençol freático, a localização de jazidas de material para cobertura;

- Estudos hidrológicos e hidrogeológicos: sobre a região e a área do aterro: as bacias e sub-bacias, os cursos d'água, cristas e talvegues, poços, fontes, surgências, linhas de marés e alagados;

- Estudos climáticos: pluviometria, o regime de chuvas e a direção-intensidade dos ventos na área do aterro; 
- Estudos de compatibilidade com a rede viária e de serviços públicos: devem indicar a largura de pistas, o estado e tipo de pavimentação; os vãos livres; os viadutos; a existência de redes de água, de energia elétrica, de esgotos e telefone;

- Estudos da legislação: possibilidades de contratos para as áreas escolhidas; orientações para compra e / ou desapropriações; visão global da legislação federal, estadual e municipal que possam afetar a área escolhida.

A normatização técnica referente à elaboração de critérios regionais para seleção de áreas para implantação de aterros sanitários data de 1997 - NBR 13896 (ABNT, 1997).

Composta por vários critérios, esta norma tem sido utilizada pela Companhia de Tecnologia de Saneamento Ambiental (CETESB), no licenciamento de aterros sanitários.

De acordo com a NBR 13896 (ABNT, 1997) para selecionar um local para fins de aterro de resíduos não perigosos deve-se considerar que o impacto ambiental oriundo da instalação do aterro seja mínimo; que a aceitação da população quanto à instalação do aterro em determinado local seja maximizada; que a área selecionada esteja de acordo com o zoneamento da região; e que a área permita utilização por um longo espaço de tempo, com necessidade de um mínimo possível de obras para o início da operação no local.

Rocha et al (2010) aponta entre os maiores problemas para a implantação de aterros sanitários:

[...] a possibilidade de poluir o solo e cursos d'água superficiais ou subterrâneos; a necessidade de supervisão constante de modo a garantir a manutenção das mínimas condições ambientais e de salubridade; a geração de gases a partir da decomposição do lixo aterrado; a necessidade de terrenos disponíveis para a instalação do aterro próximos aos locais de produção do lixo, já que o custo de transporte é muito elevado na limpeza urbana em virtude do baixo peso específico do lixo; a resistência dos moradores nas cercanias do aterro que, muitas vezes, por não serem ouvidos e devidamente esclarecidos quanto ao problema, acaba por criar impasses desgastantes para as administrações municipais. (ROCHA, et al, 2010).

Para a avaliação da adequabilidade de um determinado local aos critérios apresentados na NBR 13896, há de se fazer diversas considerações técnicas: quanto à topografia, fator determinante na escolha do método construtivo e nas obras de 
terraplanagem para a construção do aterro; quanto à geologia e tipos de solos existentes, importantes na determinação da capacidade de depuração do solo e da velocidade de infiltração; quanto aos recursos hídricos devido à possibilidade de influência do aterro na qualidade e no uso das águas superficiais e subterrâneas próximas; quanto à vegetação, devido ao seu potencial de contribuição na redução da erosão, da formação de poeira e transporte de odores; quanto ao acesso e à distância mínima dos núcleos populacionais, onde será feita a coleta dos resíduos; quanto ao tamanho disponível, visto que é recomendável que um aterro tenha vida útil de no mínimo 10 anos; e quanto ao custo da construção do aterro que varia bastante de acordo com seu tamanho e seu método construtivo. (ABNT, 1997).

Assim, conforme ReCESA (2008) uma área, para ser considerada adequada, deve apresentar um conjunto de condições técnicas, econômicas e ambientais, que requer o conhecimento de uma grande quantidade de dados e informações. No entanto, geralmente tais informações não estão disponíveis para as administrações municipais tornando-se fundamental o apoio técnico e científico de pesquisadores e instituições.

Estudos recentes têm abordado esta temática com bastante eficiência. Autores como Nunes (2002), Brollo (2001), Samizawa (2006), Lino (2007), Nunes, et al (2008) e Rocha et. al (2010) tem apresentado importantes contribuições na busca dos critérios a serem utilizados para a seleção de áreas aptas à instalação de aterros sanitários. Nos trabalhos destes autores, de maneira geral, são utilizados como critérios de pré-escolha das áreas, aqueles referenciados no Manual de Gerenciamento Integrado do IPT/CEMPRE $(1995 ; 2001)$.

Rocha et. al (2010) traz contribuições de detalhes sobre os critérios do meio físico, legais e socioeconômicos, Nunes (2002) enfatiza a importância da contribuição geomorfológica, geológica (morfoestruturas e hidrogeologia), pedológica e climática, e os demais autores destacam, dentre elementos já citados, a poderosa contribuição das geotecnologias neste processo.

A partir destes autores, os critérios do meio físico podem ser organizados em: 
- Dados geológico-geotécnicos: são informações sobre as características dos materiais que compõem o substrato dos terrenos, tendo como principais aspectos de interesse: distribuição e características das unidades geológico-geotécnicas que ocorrem na região e as principais feições estruturais, como foliação, falhas e fraturas;

- Dados pedológicos: são informações sobre as características e distribuição dos solos na região estudada, devendo ser observados os tipos de solo de ocorrem na região e a identificação dos tipos de solo mais apropriados como material de empréstimo;

- Dados geomorfológicos: são informações sobre as formas e à dinâmica do relevo do terreno, devendo ser estudada a compartimentação geomorfológica e as características das unidades que compõe o relevo, como áreas de morros, planícies, encosta, entre outras;

- Dados sobre as águas subterrâneas e superficiais: são dados sobre o comportamento natural da dinâmica e química das águas subterrâneas e superficiais de interesse para o abastecimento da população, com destaque para a profundidade do lençol freático, a localização das zonas de recarga das águas subterrâneas, os principais mananciais, bacias e corpos d'água de interesse ao abastecimento público e áreas de proteção de manancial;

- Dados sobre o clima: são dados sobre as chuvas, temperatura e ventos, com destaque para o regime de chuvas e precipitação pluviométrica (série histórica) e direção e intensidade dos ventos.

$\mathrm{Na}$ tabela 1, Nunes (2002) faz um detalhamento de aspectos geomorfológicos, climáticos e socioeconômicos para a escolha de áreas para a construção de aterros sanitários. O autor destaca também os fatores relacionados às características do solo, da geologia e da hidrogeologia numa análise integrada da paisagem. 
Tabela 1. Elementos e fatores naturais e sociais determinantes na disposição de resíduos sólidos urbanos em aterro sanitário.

\begin{tabular}{|c|c||}
\hline Elementos Naturais & Fatores Naturais \\
\hline Relevo & $\begin{array}{r}\text { Morfologia, posição, inclinação/declividade, exposição, } \\
\text { movimentos de massa, erosão. }\end{array}$ \\
\hline Rochas & $\begin{array}{c}\text { Composição, granulação, estruturação, profundidade do } \\
\text { lençol freático, porosidade, permeabilidade, transmissividade. }\end{array}$ \\
\hline Solo & $\begin{array}{c}\text { Composição, granulação, estruturação, textura, porosidade. } \\
\text { Drenagem, permeabilidade do solo. }\end{array}$ \\
\hline Oxigênio & $\begin{array}{c}\text { Precipitação, distribuição, evaporação, solo, profundidade do } \\
\text { lençol freático, drenagem (densidade e padrão), direção. }\end{array}$ \\
\hline Água & Composição, estrutura, ausência ou presença. \\
\hline Cobertura Vegetal & $\begin{array}{c}\text { Latitude, altitude, exposição, espessura da cobertura de sôo, } \\
\text { nebulosidade, umidade atmosférica, poluição atmosférica. }\end{array}$ \\
\hline Radiação solar & $\begin{array}{c}\text { Latitude, altitude, exposição e constituição e espessura do } \\
\text { solo. }\end{array}$ \\
\hline Temperatura & $\begin{array}{c}\text { Exposição, latitude, altitude, relevo, continentalidade, } \\
\text { direçacaño e freqüência. }\end{array}$ \\
\hline Vento &
\end{tabular}

\begin{tabular}{|c|c|c|}
\hline \multicolumn{2}{|c|}{ Elementos Sociais } & Fatores Sociais \\
\hline \multirow{5}{*}{ 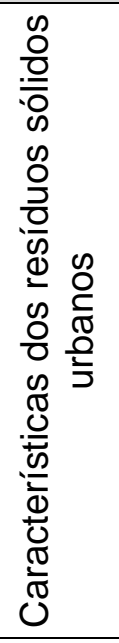 } & $\begin{array}{l}\text { Quantidade e } \\
\text { qualidade de } \\
\text { resíduos gerados }\end{array}$ & $\begin{array}{l}\text { Taxa de geração por habitante, renda percapta diferenciada } \\
\text { por classe social, hábitos da população, tipos de recicláveis } \\
\text { (orgânicos e inorgânicos) }\end{array}$ \\
\hline & Doenças & $\begin{array}{l}\text { Proliferação de micro e macrovetores transmissores, como } \\
\text { insetos e roedores. }\end{array}$ \\
\hline & Cobertura do lixo & Tipos de solo, cobertura de solo, espessura do corpo de lixo. \\
\hline & Odor & $\begin{array}{l}\text { Composição física e química dos resíduos, umidade, } \\
\text { temperatura, precipitação, evapotranspiração, drenagem de } \\
\text { percolados, granulometria e estruturação das rochas, grau de } \\
\text { compactação. }\end{array}$ \\
\hline & Lixiviados (chorume) & $\begin{array}{l}\text { Composição física e química dos resíduos, umidade, } \\
\text { temperatura, precipitação, evapotranspiração, drenagem de } \\
\text { percolados, granulometria e estruturação das rochas, } \\
\text { Morfologia do relevo, grau de compactação. }\end{array}$ \\
\hline
\end{tabular}




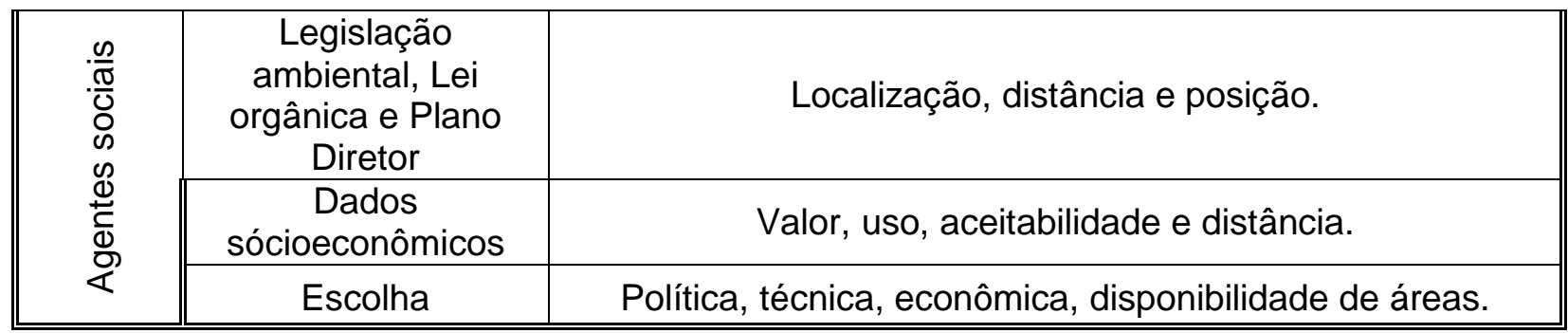

Fonte: Nunes (2002).

Os critérios socioeconômicos são informações sociais e econômicas relevantes nas tomadas de decisões sobre a escolha das áreas para instalação de aterros sanitários, como por exemplo: o valor da terra, o uso e ocupação do solo, a distância da área com relação aos centros atendidos, a integração à malha viária e aceitabilidade da população e de suas entidades organizadas.

Já os critérios legais estão relacionados aos dados sobre Legislação: que são informações sobre as leis ambientais (federais, estaduais e municipais), como, localização das áreas de proteção ambiental, áreas de proteção de mananciais, parques, reservas, áreas tombadas pelo patrimônio histórico; e informações sobre o zoneamento urbano das cidades estudadas.

Ponderar os diversos dados acima discutidos e realizar sua integração nos permite identificar áreas mais favoráveis, que através de estudos a campo podem ser confirmadas e indicadas para a instalação de aterros.

Para a integração dos dados Brollo (2001), Samizawa (2006) e Rocha et. al (2010) tem apresentados propostas de estudos ambientais para seleção de áreas favoráveis à construção de aterros, baseadas no uso da cartografia temática associada às geotecnologias como os Sistemas de Informações Geográficas (SIGs). Dentre as possibilidades existentes, a seguir apresentamos dados sobre a cartografia geomorfológica.

\section{A CARTOGRAFIA GEOMORFOLÓGICA}


Para Guerra (2001), a geomorfologia é a ciência que estuda as formas do relevo, a sua gênese, estrutura, natureza das rochas, o clima das regiões e as diferentes forças endógenas e exógenas que, de forma geral, atuam como fatores modeladores do relevo terrestre; e a cartografia geomorfológica torna-se então, um importante meio de comunicação e análise dos resultados obtidos para essa ciência. Nesse contexto, as diversas análises geomorfológicas tornam-se muito mais ricas e melhor entendidas quando são acompanhadas de documentos cartográficos nos quais estejam espacializadas.

Doné (1981) defende que através das cartas geomorfológicas é possível obter mais clareza dos objetos e fenômenos estudados e suas correlações. Elas podem auxiliar na ordenação do espaço, no agrupamento de diversos fatos geomorfológicos e também na caracterização regional, tornando-se indispensáveis ao conhecimento científico e às atividades práticas durante as mais diversas fases de pesquisa e modificação da superfície terrestre.

Assim, os mapeamentos geomorfológicos têm sido priorizados em projetos de Gerenciamento Ambiental, e que, quando acompanhados, de uma detalhada legenda, podem apoiar as tomadas de decisão. Um exemplo apresentado pelo autor é a elaboração de projetos de Estudos de Impacto Ambiental e Relatórios de Impacto Ambiental, que em sua maioria, apresentam conteúdos alicerçados em bases geomorfológicas. (ARGENTO, 2007).

Outro destaque para os mapas geomorfológicos é sua atual ligação com o Sensoriamento Remoto para efeitos de caracterização e mapeamento do relevo. As fotografias aéreas, por exemplo, tem sido muito utilizadas em procedimentos de interpretação visual. E atualmente, diversos novos sensores tem obtido dados das mais variadas resoluções espaciais nas faixas espectrais do visível, do infravermelho e de microondas. Além disso, tem empregado métodos fotogramétricos e radargramétricos que permitem a geração de pares estereoscópicos e a extração de Modelos Digitais de Elevação (MDEs). (GILES \& FRANKLIN, 1998 apud CAMARGO, et al 2011) e (Toutin \& Gray, 2000 apud CAMARGO, et al 2011). 
No entanto, autores como Silva e Rodrigues (2009) chamam nossa atenção para o fato das tecnologias relacionadas ao sensoriamento remoto, não dispor de muitos recursos didáticos para facilitar o aprendizado, sendo escassos os trabalhos que ofereçam orientações ao aprendizado de Cartografia Geomorfológica e que ao mesmo tempo ofereçam metodologias e técnicas de mapeamento.

Um dos mais reconhecidos procedimentos metodológicos para a elaboração de mapeamentos geomorfológicos foi organizado por Jurandyr L. S. Ross (1992). Trata-se dos táxons.

Segundo Ross (1992):

[...] a cartografação geomorfológica deve mapear concretamente o que se vê e não o que se deduz da análise geomorfológica, portanto em primeiro plano os mapas geomorfológicos devem representar os diferentes tamanhos de formas de relevo, dentro da escala compatível. Em primeiro plano deve-se representar as formas de diferentes tamanhos e em planos secundários, a representação da morfometria, morfogênese e morfocronologia, que têm vínculo direto com a tipologia das formas. (ROSS, 1992).

Dessa forma, para o autor, a escala de abordagem deve ser considerada essencialmente importante para as análises geomorfológicas. Ele propõe a classificação taxonômica do relevo apoiada no aspecto fisionômico das diferentes formas e tamanhos de relevo, baseado na gênese e na idade dessas formas, tendo em vista o significado morfogenético e as influências estruturais e esculturais no modelado. (SILVA e RODRIGUES, 2009).

A classificação em táxons se dá da seguinte maneira:

10 táxon: Unidades Morfoestruturais. É a maior forma de relevo, sua idade e história genética são mais antigas que as Unidades Morfoesculturais esculpidas em seu interior. Exemplo: Bacia Sedimentar do Paraná.

2ํㅡㄴ táxon: Unidades Morfoesculturais. São de dimensões inferiores às das Unidades Morfoestruturais, e com idade bem menor. Exemplos: Planalto Paranaense, Depressão Periférica Paulista. 
3 táxon: Unidades Morfológicas ou de Padrões de Formas Semelhantes. Estas retratam um determinado aspecto fisionômico decorrente das influências dos processos erosivos mais recentes e posteriores àqueles que esculpiram os planaltos e depressões. Exemplos: Padrão em morros, Padrão em colinas.

4ำ táxon: Tipos de formas de relevo. Referem-se a cada uma das formas de relevo encontradas nas Unidades Morfológicas ou de Padrões de Formas Semelhantes. Exemplo: Em um Padrão em morros, cada morro que faz parte desse padrão possui características que o diferencia dos demais.

5 táxon: Tipos de Vertentes. Representa os tipos de vertentes contidas em cada forma de relevo, sendo assim, de gênese e idade mais jovens. Exemplos: vertentes côncavas, convexas, aguçadas, etc.

6 táxon: Formas de processos atuais. Refere-se às formas de relevo bem menores e muito mais recentes, que surgem ao longo das vertentes por processos geomórficos e até mesmo por ação antrópica. Exemplos: sulcos, ravinas, voçorocas.

Para Ross (1992) apud Silva e Rodrigues (2009), as Unidades Morfoestruturais constituem as estruturas que sustentam o relevo e os aspectos esculturais constituem as Unidades Morfoesculturais. Demonstrando serem as morfoestruturas e as morfoesculturas, resultados da ação dinâmica dos processos endógenos e exógenos.

O relevo é um importante elemento para a compreensão das inter-relações entre as estruturas litológicas, o clima, a vegetação, os solos e a hidrografia, e também sobre como esses fatores condicionam as atividades humanas (FERREIRA, 2005).

A geomorfologia está diretamente relacionada às formas do relevo. Assim, o mapa geomorfológico se articula com o tema principal deste texto, constituindo-se num dos elementos indispensáveis para o estudo de áreas adequadas à instalação de aterros sanitários.

Não são aconselháveis para implantação de aterros sanitários, áreas que apresentam formas bastante onduladas e íngremes (colinas, serras, encostas). Ao contrário, relevos que apresentam formas suaves e onduladas com declives próximos aos recomendados pela NBR 13.689 podem se configurar em áreas adequadas. Já áreas com relevos de 
dunas, várzeas, restingas, terraços, mesmo apresentando forma plana, não são indicadas. As declividades com faixas inferiores a $1 \%$ também devem ser descartadas. E é a partir dos estudos geomorfológicos aplicados à seleção de áreas para a construção de aterros que se pode identificar tais áreas. (SILVA e RODRIGUES, 2009).

\section{O CONSÓRCIO ENTRE MUNICÍPIOS PARA A INSTALAÇÃO DE ATERROS SANITÁRIOS: UMA ALTERNATIVA PARA MUNICÍPIOS DE PEQUENO PORTE}

Para análise da viabilidade técnica e econômica de instalação de aterros sanitários devemos também considerar a possibilidade dos municípios atuarem de forma consorciada.

A Lei Federal 12.305 de 02 de agosto de 2010, que institui a Política Nacional de Resíduos Sólidos, em seu artigo 18, $\S 1^{\circ}$ tem como um dos objetivos priorizar, no acesso aos recursos da União, os municípios que optarem por soluções consorciadas para a gestão dos resíduos sólidos, incluído a elaboração e implementação de plano intermunicipal, ou que se inserirem de forma voluntária nos planos microrregionais de resíduos sólidos.

Na Lei Estadual 12.300, de 16 de março de 2006, artigo 3ํㅡ, item VI, que institui a política estadual de resíduos sólidos, um dos objetivos, também constitui em incentivar a cooperação intermunicipal, estimulando a busca de soluções consorciadas e a solução conjunta dos problemas de gestão de resíduos de todas as origens.

Para SUDERHSA (2007), dentre os fatores que devem ser levados em consideração para o incentivo à implantação de consórcios intermunicipais de aterros sanitários, temos:

A melhoria da qualidade da operação dos aterros, evitando que se tornem lixões e gerem desperdício do dinheiro público investido na sua implantação; menor número de áreas utilizadas como aterros sanitários (possíveis focos de contaminação quando mal operados); ganhos de escala de operação e rateio dos custos administrativos e operacionais; otimização do uso de máquinas e equipamentos no aterro; maior disponibilidade de recursos para proteção ambiental; maior representatividade na solução de problemas locais. SUDERHSA (2007). 
De acordo com Silveira e Philippi, (2008) é crescente a valorização e formalização de consórcios intermunicipais no país.

Após o advento da Lei dos Consórcios (Lei 11.107 de 06 de abril de 2005), no momento de acessar as fontes de recursos financeiros do governo federal, as iniciativas consorciadas são privilegiadas em detrimento das demandas isoladas.

Isso condiz com a busca de ganhos de escala para tornar as atividades menos onerosas no cumprimento de suas responsabilidades. O consórcio não só pode ser caracterizado como um instrumento que viabiliza o planejamento local e regional, na superação de problemas locais, como também possibilita ganhos de escala de produção com racionalização de recursos financeiros, humanos e tecnológicos. (CRUZ, 2001 apud. SILVEIRA e PHILIPPI, 2008).

Outro fator importante a ser destacado é que, as maiores iniciativas de consórcios de resíduos sólidos urbanos no Brasil estão presentes entre os municípios de pequeno porte que se encontram nas faixas populacionais de até 20.000 habitantes, conforme classificação adotada pelo IBGE (2003). (SILVEIRA e PHILIPPI, 2008).

Entendemos que, municípios de pequeno porte dispõem de áreas para a construção de aterros sanitários, mas esbarram nas dificuldades financeiras para operá-lo e mantê-lo, questão esta, que pode se configurar como viável a partir de iniciativas consorciadas.

A discussão sobre a gestão consorciada é estratégica para Rodriguez (2005), apud. Silveira e Philippi, (2008), o qual complementa falando da possibilidade de se atingir resultados positivos, com o aumento da capacidade de realização dos municípios, e, conseqüentemente, com o aumento da eficiência no uso dos recursos públicos. Além disso, a gestão associada tem um maior poder de diálogo, de pressão e de negociação, além da possibilidade de aumento da transparência nas decisões públicas. (SILVEIRA e PHILIPPI, 2008). 


\section{CONCLUSÕES}

A disposição inadequada de resíduos sólidos urbanos tem gerado um dos mais graves problemas ambientais de nosso tempo, com a poluição do solo, do ar e dos recursos hídricos, fazendo-se necessária a busca de soluções que possam minimizar o impacto da disposição destes.

Várias são as áreas do conhecimento que podem contribuir para o desenvolvimento de metodologias para a escolha de áreas adequadas à construção de aterros sanitários, dentre elas: a geomorfologia, a geologia, a hidrogeologia, a climatologia e a pedologia; além de critérios sócioeconômicos e legais.

Dentre os elementos apresentados neste texto, destacamos a cartografia geomorfológica que, atrelada ao geoprocessamento tem se mostrado como uma técnica importante para se chegar a resultados mais precisos e confiáveis, possibilitando integrar dados de campo, laboratório e documentos cartográficos, visando o fornecimento de informações importantes para os administradores municipais.

Assim, os municípios, em especial aqueles de pequeno porte, que não provem de recursos suficientes para instalar e manter um aterro sanitário, podem apontar áreas com boas condições para que possam ser operadas conjuntamente por municípios a partir de consórcios de aterros sanitários, tendo como benefícios, entre outros, custos de transporte os mais baixos possíveis, divisão dos gastos e compartilhamento de melhores condições ambientais e de saúde pública.

\section{BIBLIOGRAFIA}

ABAR - AGÊNCIA BRASIL (2013). Apenas 30\% dos municípios devem concluir os planos de saneamento básico em 2013. Disponível em: http://memoria.ebc.com.br/agenciabrasil/noticia/2013-11-03/apenas-30-dos-muni cipios- 
devem-concluir-os-planos-de-saneamento-basico-em-2013. Acesso em: 21 de dezembro de 2013.

ABNT - ASSOCIAÇÃO BRASILEIRA DE NORMAS TÉCNICAS. Aterros de resíduos não perigosos - Critérios para projeto, implantação e operação. 1997. Disponível em: $\mathrm{ftp}: / /$ ftp.cefetes.br/cursos/MetalurgiaMateriais/Joseroberto/P\%D3S/NORMAS,\%20ARTIGO S\%20E\%20\%20EXERC\%CDCIOS/nbr13896.pdf. Acesso em: 02 de dezembro de 2013.

ARGENTO, M. S. 2007. Mapeamento geomorfológico. In: Guerra, A. J. T.,Cunha, S. B. (Org.). Geomorfologia: uma atualização de bases e conceitos. $7^{\underline{a}}$ ed.. Rio de Janeiro. Ed. Bertrand Brasil, p. 365-391.

BROLLO, M. J. Metodologia automatizada para seleção de áreas para disposição de resíduos sólidos. Aplicação na Região Metropolitana de Campinas (SP). (Tese de Doutorado) Pós-graduação Saúde Ambiental, Faculdade de Saúde Pública da Universidade de São Paulo. São Paulo, 2001. 213p.

BROLLO, M. J. Seleção de áreas para implantação de aterros sanitários. In: RESID'2004 Seminário sobre Resíduos Sólidos. CD-ROM. São Paulo: ABGE, 2004.

CAMARGO F. F., et al. Mapeamento geomorfológico com imagens estereoscópicas digitais do sensor ASTER/TERRA. São Paulo, UNESP, In: Revista de Geociências, v. 30, n. 1, p. 95-104, 2011. Disponível em: http://drifte.rc.unesp.br/revistageociencias/30_1/Art\%2008_Camargo.pdf. Acesso em: 15 de dezembro de 2011.

CASEIRO, A. H. e QUITHO, L. Utilização de aterro sanitário para destinação final de resíduos sólidos gerados nos grandes centros urbanos: Aterro Bandeirantes. Exacta. v. 2, p. 191-202. São Paulo: Uninove, nov. 2004.

DADOS DEMOGRÁFICOS dos municípios brasileiros. INSTITUTO BRASILEIRO DE GEOGRAFIA E ESTATíSTICA on-line. 2005. Apresenta informações censitárias dos municípios brasileiros. Disponível em: <http://www.ibge.com.br/. > Acesso em: 12 mar. 2003.

DIÁRIO OFICIAL DA UNIÃO. LEI FEDERAL № 12.305, DE 2 DE AGOSTO DE 2010. Política Nacional de Resíduos Sólidos. Disponível em: http://www.abinee.org.br/informac/arquivos/lei12305.pdf. Acesso em: 05_10_2010.

DIÁRIO OFICIAL DA UNIÃO. DECRETO № 7.404, DE 23 DE DEZEMBRO DE 2010. Regulamenta a Lei $n^{\circ}$ 12.305, de 2 de agosto de 2010. Disponível em: http://www.planalto.gov.br/ccivil_03/_ato2007-2010/2010/Decreto/D7404.htm. Acesso em: 05_02_2011. 
DIÁRIO OFICIAL DA UNIÃO. LEI № 11.107, DE 6 DE ABRIL DE 2005. Normas Gerais de Contratação de Consórcios Públicos. Disponível em: http://www.nucleourbanizacao.com.br/09/003.pdf. Acesso em: 05_10_2010.

DIÁRIO OFICIAL DO ESTADO DE SÃO PAULO. LEI ESTADUAL № 12.300, DE 16 DE MARÇO DE 2006. Política Estadual de Resíduos Sólidos. Disponível em: http://www.ambiente.sp.gov.br/legislacao/estadual/leis/2006\%20Lei\%2012300.pdf. Acesso em: 05_10_2010.

FERREIRA, I. L. Mapeamento Geomorfológico da Bacia Hidrográfica do Médio e Alto Paranaíba. Relatório final, iniciação científica. Universidade Federal de Uberlândia. Uberlândia: Instituto de Geografia. 2005.

FUNDAÇÃO ESTADUAL DO MEIO AMBIENTE (FEAM). Como destinar os resíduos sólidos urbanos. Belo Horizonte: Feam, 2002. 45p.

GUERRA, A T. e GUERRA, A J. T. Novo dicionário geológico-geomorfológico. Rio de Janeiro: Bertrand Brasil, 1997. $648 \mathrm{p}$.

GUERRA, A. J. T. \& CUNHA, S. B. (Org.). Geomorfologia e Geoprocessamento. In: Geomorfologia, uma atualização de bases e conceitos. $4^{a}$ edição. Rio de Janeiro: Bertrand Brasil, 2001. p. 393-414.

GUERRA, A. J. T. \& CUNHA, S. B. (Org.). Mapeamento Geomorfológico. In: Geomorfologia, uma atualização de bases e conceitos. 4ª edição. Rio de Janeiro: Bertrand Brasil, 2001. p. 365-392.

HENDGES, Silvio. Diagnóstico dos resíduos sólidos no Brasil. Disponível em: Ecodebate, on-line: http://www.ecodebate.com.br/2011/11/17/diagnostico-dos-residuos-solidos-nobrasil-artigo-de-antonio-silvio-hendges/. Acesso em: 15 de dezembro de 2011.

JARDIM, N. S. Lixo municipal: manual de gerenciamento integrado. São Paulo: Instituto de Pesquisas Tecnológicas, 1995.

LEI ESTADUAL. Lei Estadual 12.300, de 16 de março de 2006, artigo 3o, item VI. Disponível em: http://www.cetesb.sp.gov.br/licenciamentoo/legislacao/estadual

/leis/2006. Acesso em: 01_10_10.

LIMA, J. D. Gestão de resíduos sólidos urbanos no Brasil. João Pessoa: ABES, 2002. 183 p.

LINO, I. C. Seleção de áreas para implantação de aterros sanitários: análise comparativa de métodos. Dissertação (mestrado) - Universidade Estadual Paulista, Instituto de Geociências e Ciência Exatas. Rio Claro: [s.n.], 2007. 
NUNES, João Osvaldo Rodrigues. Uma contribuição metodológica ao estudo da dinâmica da paisagem aplicada a escolha de áreas para a implantação de aterro sanitário em Presidente Prudente - SP. Presidente Prudente, 2002. Tese (Doutorado em Geografia), Universidade Estadual Paulista, Faculdade de Ciências e Tecnologia, 2002.

NUNES, J. O. R. et al. Contribuição do conhecimento geomorfológico para as análises em SIG: seleção de áreas para construção de aterro sanitário no município de Presidente Prudente - SP - Brasil. In: Geomorfologia: aplicação e metodologias. São Paulo: Expressão Popular, 2008.

ROCHA, C. H. B. Geoprocessamento aplicado à seleção de locais para a implantação de aterros sanitários: o caso de Mangaratiba-RJ. In: Geoprocessamento e análise ambiental: aplicações. 4⿳亠丷a ed. Rio de Janeiro: Bertrand Brasil, 2010.

ROSS, J. L. S. O registro cartográfico dos fatos geomorfológicos e a questão da taxonomia do relevo. In: Revista do Departamento de Geografia. São Paulo: Edusp. n.6, 17-30p. 1992.

SAMIZAVA T. M. Utilização de técnicas de geoprocessamento para seleção de áreas potenciais para instalação de aterro sanitário no município de Presidente Prudente - SP. Presidente Prudente, 2006. Monografia (Bacharelado em Engenharia Ambiental). Universidade Estadual Paulista. Faculdade de Ciências e Tecnologia.

SECRETARIA DO MEIO AMBIENTE. Aterro em valas. Disponível em: http://ambiente.sp.gov.br/valas/index.htm. Acesso em: 01_10_10.

SILVA, T. I e RODRIGUES, S.C. Tutorial de cartografia geomorfológica: ARCGIS 9.2 e ENVI 4.0. Man. Técnicos - Rev. Geogr. Acadêmica, v.3, n.2, 2009.

SILVEIRA, R. C. E. e PHILIPPI, L. S. Consórcios Públicos: uma alternativa viável para a gestão regionalizada de resíduos sólidos urbanos. In: Revista de Desenvolvimento Regional (REDES). Santa Cruz do Sul, v. 13, n. 1, p. 205 - 224, jan./abr. 2008. Disponível em: http://online.unisc.br/seer/index.php/redes/index. Acesso em: 01_10_2010.

SUPERINTENDÊNCIA DE DESENVOLVIMENTO DE RECURSOS HÍDRICOS E SANEAMENTO AMBIENTAL (SUDERHSA). Consórcios Intermunicipais de Resíduos Sólidos Urbanos, 2007. Disponível em: http://www.suderhsa.pr.gov.br. Acesso em: 01_10_2010.

SUZUKI, J. A. N. e GOMES, J. Consórcios intermunicipais para a destinação de RSU em aterros regionais: estudo prospectivo para os municípios no Estado do Paraná 2009. In: Revista de Engenharia Sanitária Ambiental. v.14 n.2 abr/jun 2009. 